\title{
Culturas y literaturas de África y América: algunos nexos*
}

\author{
Culturas e literaturas de África e América: alguns nexos
}

\author{
Ana Pizarro \\ Carolina Benavente \\ Universidade de Santiago do Chile - Santiago do Chile - Chile
}

\begin{abstract}
Resumen: En este artículo se esbozan algunos vínculos culturales y literarios entre África y América asumiendo que estos continentes tienen una común historia de relación colonial. Por una parte, se señala una presencia africana concreta en América a través de la esclavitud. Esta presencia estuvo acompañada de un racismo que hoy persiste, pero ella también aportó sólidos imaginarios y prácticas de apertura tales como las músicas mulatas, el cimarronaje, el creol y la creolización, entre otros. En la actualidad, se observa la instauración problemática de algunos nuevos vínculos turísticos, mediáticos y artísticos de América con África en el contexto global. Por otra parte, se exploran las articulaciones literarias entre ambos continentes desde inicios del siglo XX, a través del influjo de las vanguardias, la negritud, los escritores caribeños, los procesos de descolonización, la asunción de la oralidad y de una escritura de la diferencia cultural. Se termina constatando la paradoja de un vínculo metropolitano colonial que hoy, más que antes, facilita los acercamientos y las comparaciones, a la vez que sigue condicionando la producción literaria y cultural de ambos continentes.
\end{abstract}

$\diamond$

Palabras clave: África; América Latina; Literatura; Comparatismo; Cultura

Resumo: Neste artigo, esboçam-se alguns vínculos culturais e literários entre a África e a América, assumindo que esses continentes têm uma história comum de relação colonial. Por uma parte, assinala-se uma presença africana concreta na América através da escravidão. Essa presença esteve acompanhada de um racismo que hoje ainda persiste, mas ela também trouxe sólidos imaginários e práticas de abertura tais como as músicas mulatas, o cimarronaje, o criolo e a criolização entre outros. Na atualidade, observa-se a instauração problemática de alguns novos vínculos turísticos, midiáticos e artísticos da América com a África no contexto global. Por outra parte, exploram-se as articulações literárias entre ambos os continentes desde o início do século XX, através do influxo de vanguardas, de negritude, de escritores caribenhos, de processos de descolonização, de assunção da oralidade e de uma escritura da diferença cultural. Concluímos constatando o paradoxo de um vínculo metropolitano e colonial que hoje, mais que antes, facilita as aproximações e as comparações, uma vez que segue condicionando a produção literária e culturas de ambos os continentes.

Palavras-chave: África; América Latina; Literatura; Comparatismo; Cultura

Antes de comenzar a estudiar el África subsahariana en el siglo XX, fuimos construyendo en América Latina diferentes imágenes sobre este universo que, resultándonos tan cercano, nos era tan distante geográficamente. Pues todo encuentro entre culturas, directo, indirecto, mediado

\footnotetext{
* Este artículo es el capítulo introductorio de: BENAVENTE, Carolina. PIZARRO, Ana (Eds.). África/América: literatura y colonialidad. Santiago: FCE, 2014 (previsto). Su redacción se llevó a cabo como parte del proyecto Fondecyt 1101018 año 2010 tres años "Conformación de discursos culturales en áreas de historia colonial: América Latina, 1910/2010", patrocinado por el Instituto de Estudios Avanzados de la Universidad de Santiago de Chile.
}

o no, genera respuestas en el imaginario por medio de las cuales vamos plasmando, orientando y materializando nuestra relación con el otro. Pero estas respuestas, a su vez, dependen del tipo de encuentro protagonizado y, en el caso del nuestro con el continente africano, él se llevó principalmente a cabo en el marco de la esclavitud, que es una de las formas que asume el colonialismo. Tenemos también una relación previa con el norte de África, por los siglos de permanencia de los árabes en la península ibérica antes de su Reconquista. Y, debido a la expansión colonial y comercial impulsada por Enrique el Navegante, 
la que condujo a los portugueses a recorrer el litoral subsahariano desde inicios del siglo XV, podríamos decir que nuestra relación cultural con esta geografía sería más antigua de lo que parece. Sin embargo, la esclavitud ha dejado en nosotros una mayor y singular impronta, la que concierne en especial al África subsahariana en su porción occidental, pues de allí, por su cercanía con Europa y América, provenían en su casi totalidad los esclavos importados a América. Esto es, la esclavitud imprimió un molde específico a nuestra relación con el África "negra" vecina del Atlántico, en el marco de la relación colonial que nos subordinó a ambas triangularmente a Europa.

¿Cuál es la singularidad de esta impronta con que el esclavismo y el colonialismo han moldeado las relaciones África/América? Al intentar hilvanar una respuesta a esta interrogante, vamos a comenzar entregando una visión sobre los mecanismos culturales para después enfocar lo relativo al fenómeno literario.

Tal vez, y por evidente que parezca, la primera característica de esta relación sea la de una concreta presencia africana en nuestro continente. Si bien la práctica de la esclavitud ha existido en muy diferentes períodos y lugares, iniciándose en América en rigor con el traslado de indígenas taínos en grandes cargamentos a Europa, se trató en el caso africano de una esclavitud masiva y sostenida en el tiempo por medio de la cual se buscó asegurar una mano de obra adaptada a las necesidades de la economía colonial. El dramático descenso en la magnitud de la población indígena posterior a la conquista, sobre todo en Las Antillas, justificó a los ojos del colonialismo la necesidad de importar otra fuerza de trabajo que pudiera dedicarse a las labores agrícolas del monocultivo. Así, si bien encontramos esclavos africanos desempeñándose en tareas domésticas y artesanales, ellos sobre todo fueron incorporados a la economía de plantación que, en torno a la caña de azúcar, el algodón, el café, el cacao, el plátano, entre otros, se desarrolló sobre todo en la macrozona intertropical que incluye el mar Caribe, Centroamérica, Brasil, el sur de los Estados Unidos y la costa pacífica norte de América del Sur. Explica el antropólogo cubano Fernando Ortiz sobre las necesidades de la producción azucarera:

Una cosa era tener cañas y otra tener azúcar en cuantía comercial. Entre la producción agrícola, que ya con esa experiencia no era cuestión de braceros, y la producción mercantil que en Europa tenía el mercado asegurado y anheloso en la demanda, se interponía la producción industrial, que requería maquinarias y técnicos que aquí no existían y los cuales tenían necesariamente que ser importados de ultramar. En definitiva, se necesitaba capital para comprar esclavos, para traer maestros y oficiales de azúcar y para la maquinaria de molino, calderas, tachos y receptáculos para la decantación (ORTIZ, 1940, p. 374).
Así, como uno de los elementos requeridos para que este tipo de produccion agrícola alcanzara un nivel industrial, se importaron al continente americano unos 10 a 15 millones de africanos - las cifras varían - entre los años 1492 y 1860 , de los cuales cerca de dos tercios lo habrían sido a la América hispana y portuguesa.

En segundo lugar, nuestra relación con África está marcada por un efecto directo del colonialismo, cual es el del racismo. Las cifras que hemos entregados son elocuentes respecto de una presencia que está allí hasta el día de hoy y que, mediante sucesivos procesos de mezcla, se ha hecho constitutiva de la población americana y su cultura. Pues si bien la esclavitud africana masiva siempre fue cuestión de cifras, ella también fue generando valores y comportamientos distintivos de nuestras sociedades coloniales. Profundamente incrustada en nuestros hábitos más cotidianos, la discriminación basada en la raza y el color de piel ha sido uno de los mecanismos más poderosos de ordenamiento, disciplinamiento y control social en la modernidad, fundamentando lo que Aníbal Quijano ha llamado la "colonialidad del poder" como actualización de las relaciones incubadas en el régimen colonial. Esta discriminación no ha afectado únicamente a los africanos, sino a cualquiera que se alejara del fenotipo europeo "blanco", pero sustentó la reducción de los primeros a una mera condición instrumental.

A través de diversos discursos escritos y orales, desde las peticiones y los edictos de la conquista hasta los testimonios en procesos judiciales y las opinologías televisivas de hoy, sabemos cómo el racismo opera en nuestras visiones acerca del otro africano o negro desde los inicios de la esclavitud hasta nuestros días. En formas vulgares o más sutiles, lo vamos calificando, categorizando, clasificando sin por lo general advertirlo, simplemente repitiendo convenciones lingüísticas y culturales o, más bien, permitiendo que ellas nos repitan a nosotros mismos para mantener las distinciones instituidas por el colonialismo. Distinciones de castas entre blancos, indios, negros, mestizos, mulatos, zambos y otras categorías que jamás resultarán suficientes para nombrar la diversidad y la multiplicidad de cruces posibles de efectuarse entre seres y grupos humanos y que, con el tiempo, hemos ido reduciendo a un conjunto más acotado de sustantivos. El problema de base, y la contradicción, es que al dejar que estas categorías de uso discriminatorio permeen y moldeen nuestras relaciones con el y lo africano o "negro" en la cotidianidad, le seguimos negando la humanidad a un otro que no sólo nos es semejante, sino también constitutivo. Por ello, hablar de un "imaginario" en el caso del racismo parece un contrasentido.

Sin afán de idealizar, sino procurando vislumbrar la dinámica cultural en su carácter afirmativo de la vida, podemos decir que otra cosa sucede con la inventiva 
desplegada por los propios africanos y por quienes con ellos se mezclaron en el suelo americano. Usualmente separados de sus grupos de origen en Angola, Guinea, Cabo Verde, Benín, Senegal, Gambia, Sierra Leona o Mozambique - entre otras zonas que hoy día corresponden a distintos países africanos -, desprovistos de sus instituciones e instrumentos $\mathrm{y}$, sobre todo, privados de su libertad de acción y desplazamiento, ellos usaron de toda su imaginación para sobrevivir en el día a día e intentar diferentes vías de escape. Desde las restricciones imperantes a sus movimientos, pero explotando los deseos que despertaban sus cuerpos, así como sus propias ansias de reapropiación, dieron origen a las musicalidades que hoy en día conforman, paradójicamente, el núcleo cultural tal vez más reconocible y característico de lo americano. Samba, son, cueca, blues, tango, jazz, bolero, cumbia, rock, reggae, salsa, hip hop, merengue, dub, rumba y reggaetón, entre muchos otros, son los aportes mestizados de pueblos ágrafos y carentes de acceso a la escritura alfabética en la sociedad colonial, así como los sonidos, las letras, los pasos, las voces y los atuendos que, siendo penetrados y conformados por la cultura letrada, el mercado y las tecnologías modernas de reproducción de los sonidos y la imagen, llegaron en el siglo XX a hacerse distintivos de la modernidad porque resultan sintomáticos de sus convulsiones y sus desgarramientos. Diseminadas por tierra, aire y mar de la mano de los flujos migratorios, el turismo y las industrias culturales, circulan hoy por casi cada rincón del planeta las "músicas mulatas" que, en su estructura no lineal, rítmica, descentrada, dialógica, reiterativa, de intensificación, de improvisación, etc., nos abren "un camino donde el desarrollo cultural puede ser, además, expresión y goce corporal” (QUINTERO, 2009, p. 199).

Por obra de la esclavitud, contamos también para imaginarnos el mundo con el creol, idioma nacido en la modernidad frente a las miles de lenguas que han desaparecido de la faz de la Tierra. Fraguado en la sociedad de plantación para permitir la comunicación entre amos y esclavos, el creol, idioma oficial de Haití y que sigue siendo hablado a lo largo del Caribe, es una creación colectiva y anónima que, por ende, difiere del esperanto como propuesta individual de lenguaje universal aparecido en Europa a fines del siglo XIX. No resulta casual que en ese mismo período comience también a haber mayor interés por los estudios lingüísticos del creol, a partir de los cuales comenzó a hablarse de la creolization/créolisation/criollización/creolización como proceso de mezcla, combinación, acuerdo y recomposición anclado en la plantación esclavista y que, como tal, recoge la asimetría del poder colonial. Debido a ello y a que pone el acento en la creatividad, su uso se aparta de la connotación netamente mestiza y vernacular de lo criollo en la América hispánica. En la actualidad, la creolización tal como ha sido pensada por el martiniqués Edouard Glissant, pero también por el sueco Ulf Hannerz y el norteamericano Richard Price, entre muchos otros, se ha convertido además en un modelo para imaginar el intercambio y la creación cultural conjunta en las proliferantes, intensas e imprevisibles condiciones de contacto proporcionadas por la mundialización.

Y tenemos también una potente cultura de la fuga, basada en la huida concreta de los esclavos en forma individual o bien colectiva, cuando daba origen a los palenques, cumbes y quilombos. En el Brasil, el Quilombo dos Palmares resistió durante más de un siglo funcionando como una república autónoma, abarcando su vigencia todo el siglo XVII hasta la captura y derrota del legendario Zumbí y sus seguidores. La película de Carlos Diegues del año 1985 reinventa brillantemente esta hazaña. En Jamaica, la nota alta de la resistencia la entregan las Maroon Wars, las Guerras Cimarronas del siglo XVIII, las que también nos ponen en evidencia el afán de autonomía y el nivel de organización alcanzado por los fugitivos. Esto, pese a que el caso de los "jacobinos negros" que declaran la Independencia de Haití el año 1804, paradójicamente el único levantamiento cimarrón exitoso, nos vuelve a mostrar lo difícil que resulta conformar sociedades a partir de comunidades fracturadas y desencajadas de entrada, especialmente si se trata de ingresar en los complejos engranajes del moderno sistemamundo occidental. Pero frente a estas resistencias épicas están también las pequeñas provocaciones, seducciones y negociaciones del orden cotidiano y doméstico que han ido moldeando anónima, intersticial pero eficazmente nuestra cultura, desde los patois y las actitudes hot, hype, rude y cool hasta la institución del matrimonio surinamés como forma de escape de la mujer por medio de un uso reconvertido de su cuerpo. Pues este conjunto de prácticas pueden reagruparse mediante lo que René Depestre llamó una "cultura cimarrona" cuya "creatividad se manifestó en los campos más variados":

yendo de los métodos de trabajo agrícola a las normas del matrimonio y de la familia, de la religión al folclor, del idioma a las formas de cocinar y de alimentación, del ritual funerario a la expresión corporal dentro de las tradiciones motrices de la danza y el coito, de la magia a la farmacopea popular, de la música a la literatura oral y a los juegos de sociedad, de los peinados de las mujeres a la manera de llevar a los niños, de la mitología a la resistencia armada (DEPESTRE, 1986, p. 75-76).

La fuga, entonces, significó además otras modulaciones culturales bajo la forma de un escape hacia el mar en la perspectiva de un utópico retorno a la tierra 
de origen (Lienhard, 1998, p. 21). Puesto que la mayor parte de los esclavos habían sido recién arrancados de su lugar natal, África era una presencia inmediata en sus memorias: era un recuerdo. Y también era un mito. Un mito que sobrevivió bajo la forma de diversos cultos a los orishas Shangó, Oshún, Eleggua y sobre todo Yemanyá, la madre del agua, entre otros asociados a diversas fuerzas de la naturaleza que fueron adoptando un carácter sincrético donde les fue permitido practicarse. En la magia vudú, la figura del zombi metaforiza la misma condición del africano esclavizado: la del muerto resucitado y librado al dominio de otro en su nueva vida americana, después de la larga y oscura travesía por el océano. En décadas recientes, las circulaciones de la cultura han significado la apropiación, en América Latina, de un imaginario fraguado en la América anglófona y protestante: el etiopismo, por medio del rastafarismo jamaiquino y su aliado el reggae. Metáfora esta vez de la Tierra Prometida, ellos han propagado la rima de Etiopía con Utopía por doquier, y nos han regalado una visión alternativa del mundo en la era de la globalización.

Pero hoy en día la circulación aumenta, los flujos se multiplican y las distancias parecen acortarse. Como nunca antes estamos cerca de África o, al menos, de algunas de sus partes. A través de la prensa y la televisión, hemos sabido por décadas de las hambrunas, las epidemias, los diamantes, las permanentes guerras y la corrupción y, desde el año 2009, nos confirma esta información la realización del publicitado rally París Dakar a través de Chile, Argentina, Perú y Bolivia. Pero la relocalización de esta clásica carrera automovilística en Sudamérica, cuyo nombre se ha recortado simplemente al de rally Dakar, nos entrega además conocimiento de una función que "nos une" y a la vez nos divide a África y a América, a Chile y a Senegal, en la competencia por una fracción de la nueva escena global. Esta nueva función es la de ser destinos y telones de fondo privilegiados del deporte y el turismo aventura occidentales. Ellos se solazan en los todavía suficientemente agrestes paisajes de la periferia $y$, por medio de objetos de merchandising que exhiben el logo del turbante tuareg sin ojos, sin rostro y sin cuerpo, como una cáscara mágica que pudiese revestir de misterio a cualquier habitante del planeta, es comercialmente explotado hasta el hartazgo en esta dimensión exotista y en el deseo de otredad que comporta.

Al mismo tiempo, despunta en el rally Dakar una cara insospechada de África, pero sobre la cual cayeron todos los reflectores y cámaras el año 2010, cual es la de su modernización, su democratización y su desarrollo. A través de la realización en Sudáfrica de la XIX Copa Mundial de Fútbol y la "exhibición de determinación y orgullo de la nación del arco iris, que trasladó un mensaje de esperanza a un continente entero" (FIFA, 2010) se nos proyectó, entre la algarabía de las vuvuzelas y bajo la mirada de los edificios corporativos, una imagen bastante distinta de la que nos formamos al conocer la lucha de Nelson Mandela contra el apartheid o los lazos militares y comerciales que mantuvo con él la dictadura de Augusto Pinochet. Hoy, liberados del estigma segregacionista, recorren el mundo los artistas sudafricanos: Neill Blomkamp, realizador de esas futuristas fábulas transtercermundistas que son las películas Distrito 9 (2009) y Elysium (2013); Die Antwoord, la rupturista, alienígena y divertida banda que explora una atrofiada blanquitud en los códigos y actitudes zef de los suburbios de Johannesburgo; y los fotógrafos Pieter Hugo y Nontsikelelo Veleko, únicos exponentes del arte contemporáneo africano incluidos en la reciente muestra itinerante del Museo Etnológico de Berlín. Ellos nos muestran respectivamente los efectos eclécticos de la modernización en los jóvenes de la capital y la posibilidad de "[jugar] con la imagen de África como un continente exótico y extraño donde se practican rituales tenebrosos" (CCPLM, 2013).

Sobresale en estos artistas blancos sudafricanos su acercamiento hacia América Latina al elaborar su lugar en el mundo, complicidad que sostiene articulaciones transnacionales y translocales que, si bien se establecen a través de los más modernos dispositivos mediales, conllevan un descentramiento respecto de un eje de relacionamiento metropolitano. Mediante jirones culturales, posiciones dislocadas, miradas periféricas y fragmentarias, la globalización se está imaginando a sí misma de otra manera desde las experiencias violentas y traumáticas del imperialismo, el colonialismo y la esclavitud. En los islotes latinoamericanos de modernidad, estas búsquedas que oscilan entre las grandes y las pequeñas epopeyas, el humor y la violencia, el simulacro y la realidad, lo masivo y lo popular, el barrio y el planeta, la delincuencia y la resistencia, el tercermundismo y el ciberpunkismo nos anuncian un futuro común que ya está, así como un pasado que sigue estando presente.

Estas articulaciones que se establecen desde Sudáfrica y en las cuales participamos con entusiasmo desde Sudamérica son, sin embargo, los despuntes más actuales de procesos recíprocos de cuestionamiento, comparación $\mathrm{y}$ acercamiento que, como hemos visto, se inician desde el primer momento de la esclavitud y que en el último siglo han encontrado un lugar en la literatura como forma verbal "docta" de registro, inscripción, pensamiento y afección. Pues desde a lo menos los comienzos del siglo XX empezó a haber para nosotros un espacio en el conocimiento de la literatura europea, luego latinoamericana, que nos contactó con la literatura y la cultura africanas. Un lugar lejano y ajeno porque es evidente que, entre los sectores criollos de América Hispana, no nos identificábamos con el África subsahariana ni la conocíamos como un 
continente literario-cultural. Y también porque en los países del Pacífico y del sur la información era aún menor y la globalización aún no derribada distancias del modo como lo hace hoy. Un reputado crítico chileno bastante tradicional, alguna vez, en una reunión de estudiosos, nos criticó por sugerir similitudes de funcionamiento. “¿Nosotros como los africanos? ¡Qué idea!”, exclamó Fernando Alegría. Pero habituados a la mirada comparativa y lejos de pensar nuestras literaturas en la homogeneidad con que tradicionalmente las ha tratado la crítica y la historiografía, la idea no nos abandonó. Un par de estudiosos de esas literaturas nos explicaban:

A pesar de los considerables esfuerzos de la investigación, las literaturas africanas - en lenguas africanas - siguen siendo poco conocidas en su conjunto. En gran medida, esto se debe a la amplitud del dominio de estudios y a su complejidad. Entre las dificultades para elaborar una visión sintética sobre ellas, podemos mencionar las fronteras entre las áreas geográficas, las barreras entre las disciplinas de la investigación, la especialización lingüística, la dispersión de la documentación, las diferencias entre los dominiones de las literaturas orales y escritas; todos ellos son obstáculos considerables que, por lo mismo, vuelven estas literaturas difícilmente accesibles (BAUMGARDT, BOUNFOUR, 2000, p. III).

La primera aproximación a África en esta perspectiva comparada tuvo lugar por medio del estudio de las vanguardias europeas, a través de las cuales hicieron un común descubrimiento del arte africano los iniciadores de los movimientos de ruptura de comienzos del siglo XX, como Guillaume Apollinaire con sus fetiches de Oceanía y de Guinea, Pablo Picasso, con sus colecciones, o los latinoamericanos como Huidobro, que participaron allí. Los habían precedido en esta búsqueda de lo vernacular el aduanero Rousseau o Paul Gauguin. "Aún antes de la Primera Guerra Mundial - observa René Depestre -, la influencia relativa de África se extendió también a la poesía, la novela, la música" (1986:23). Algo había de profundamente auténtico en ese universo ajeno y fuertemente estético y llevaron la mirada hacia los procesos que guiaba Leo Frobenius con sus recientes investigaciones sobre las culturas africanas, de las que expresaba:

Todo comporta un objetivo preciso, áspero, severo, tectónico. He aquí el carácter del estilo africano. Cualquiera que se acerque a él al punto de comprenderlo del todo, reconoce pronto que domina toda África, como la expresión misma de su ser. Se manifiesta en los gestos de todos los pueblos negros tanto como en su plástica, habla en sus danzas como en sus máscaras, en su sentido religioso como en sus modos de existencias, sus formas de Estado y sus destinos como pueblos. Vive en sus fábulas, en sus cuentos de hadas, sus leyendas, sus mitos ${ }^{1}$ (FROBENIUS cit. KESTELOOT, 2001, p. 86).

Frobenius habla del mundo africano como de "une civilisation de l'étendue" (una civilización de la extensión), y más allá del esencialismo y del negrismo que parece surgir de su apreciación, es importante en su momento la radical afirmación positiva de esas culturas por parte de un estudioso de ellas.

Éstas contenían, en su fundamentalidad y también en su refinamiento, la expresión de culturas de enorme espesor histórico que habían indagado mucho antes que Occidente en la relación entre arte y naturaleza, en el dilema central de la representación, que, desde el difuminato de los impresionistas, atravesando por la geometrización de los cubistas o el onirismo de los surrealistas, era la gran búsqueda de ruptura con la figuración, con la reproducción de las líneas del modelo, que conducía a la abstracción. Allí estaba entonces la cuestión, en el perfil impenetrable para Europa del arte africano, en sus máscaras, sus pinturas rupestres, sus estatuas, sus petroglifos, así como en sus templos y palacios en las culturas más complejas, sus utensilios cotidianos en madera, piedra, terracota o metal. Parafraseando a Georg Lukács, se podría decir que, con la abstracción, el arte africano había dado la respuesta antes que el desarrollo histórico del espíritu se hubiera planteado la pregunta.

Jean-Paul Sartre, en 1948, escribía "Orfeo Negro", un prefacio que acarrearía una enorme discusión y se volvería un clásico de la obra de un africano, al que introducía, Leopold Sedar Senghor, senegalés, que además de buen poeta iba a dirigir posteriormente a su país. En las primeras décadas del siglo participaba con los caribeños en el perfilamiento del grupo de la Revue $d u$ Monde Noir (1931) que levantaría en París, junto con Légitime Défense (1932) al movimiento de la Negritud, de audiencia internacional. París era el centro metropolitano de los países africanos de habla francesa, pero, más que eso, era un centro de la cultura - "polo de religación", diría Ángel Rama - internacional en donde dialogarían escritores y artistas venidos de África, América del Sur, del Norte y del Caribe. Se genera en esa parte del hemisferio norte una circulación curiosa que religa a África con el Caribe, con la América Hispana, con los poetas norteamericanos, quienes también se contactan con los demás en París, trayendo su Renacimiento con ellos.

\footnotetext{
1 "Tout comporte un but précis, âpre, sevère, tectonique. Voilà le caractère du style africain. Quiconque s'approche de lui au point de le comprendre tout à fait, reconnaît bientôt qu'il domine toute l'Afrique, comme l'expression même de son être. Il se manifeste dans les gestes de tous les peuples nègres autant que dans leur plastique, il parle dans leurs danses come dans leurs masques, dans leur sens religieux comme dans leur modes d'existence, leurs formes d'État et leurs destins de peuples. Il vit dans leurs fables, leurs contes de fées, leurs légendes, leurs mythes".
} 
Más que en la "capitale du XIX" como diría Walter Benjamin, París se convierte ahora en una capital del siglo XX negro. Dada la situación de sus respectivos países, la ciudad, entonces, en su apertura al mundo de la creación, les ofrece la posibilidad de un diálogo al cual los latinoamericanos asistiríamos en forma oblicua, en nuestra propia conexión con la metrópoli instauradora de esas mediaciones todavía no cristalizadas entre el Tercer Mundo.

Los estudios hispanoamericanistas tradicionalmente no consideraron al África. Sólo Cuba y Puerto Rico, dado el importante contingente de población de origen africano que poseen, se interesaron por ella desde la primera mitad del siglo XX, y allí surgió una inflexión negrista en la producción local, fundamentalmente arraigada en la poesía. Luis Palés Matos, por una parte, Nicolás Guillén por otra, mostraron a la América Latina, junto con los ecos de Jorge de Lima en Brasil - amigo de Gabriela Mistral en los cuarenta -, la presencia de una vertiente afroamericana en nuestra cultura, importante de ser considerada. Hasta Humberto Meza Fuentes en Chile, país tradicionalmente ajeno a estas realidades que, sin embargo, le concernían más de lo que quería la burguesía agraria del Chile central que hegemonizaba la conciencia de país, fue tocado por esta vertiente.

Pero la gran corriente de afirmación de la conciencia afroamericana surgió del Caribe y se extendió, por una parte, a la América del Norte y, por otra, a Europa. El flujo hacia los Estados Unidos comenzó con la participación de Marcus Garvey, el jamaiquino, en el monumental Renacimiento de Harlem que, en los acordes del jazz, iba a experimentar la transformación de la música tradicional de su iglesia protestante, los negro spirituals, los gospels, en una multiplicidad de sonidos en fuga llevada por los vientos y la percusión, acarreados en la inflexión irreductible de la modernización norteamericana. El periplo de Garvey sería de ida y vuelta y, al regreso, traería al Caribe los ecos transformados del canto ritual. La negritud sería la materia creativa de dos poetas en los Estados Unidos, Langston Hughes y Claude Mackay, que entrarían prontamente en contacto con sus congéneres en Paris, en una peripecia tricontinental del espíritu.

La otra vertiente, la que se dirige hacia Europa, surge desde el Caribe francófono. Jean Price-Mars, por una parte, era el pionero de una actitud beligerante en la escritura, a la que se suman varios otros escritores, como Aimé Césaire y Léon Damas, el guyanés, entre varios otros, concurriendo a la publicación de Légitime Défense y la Revue du Monde Noir (1931), en conjunto con Senghor, que viene de África. En el caso de Haití, la afirmación identitaria se constituye también en respuesta a la invasión norteamericana. Para los caribeños en general en sus lugares de origen no es posible esta acción reivindicativa, es por eso que dialogan en Francia, en idas y venidas, naciendo así el movimiento circular de un hemisferio norte ahora no poderoso, sino menesteroso, con ulteriores divisiones y negaciones, que busca, ser reconocido en su humanidad.

En esta circularidad es en donde se unen las historias de las literaturas africanas y latinoamericanas. Allí es donde encuentra un punto de partida la literatura africana moderna de gesto anticolonial, pese a que los desarrollos ulteriores divergen.

Los años 1960 ven desarrollarse en los distintos países del continente africano los procesos de descolonización. Por una parte, éstos abren posibilidades libertarias que pronto se ven entorpecidas por la rémora del poder colonial, como ha sido evidenciado por diferentes narradores y cineastas, entre ellos el clásico Sembene Ousmane. Por otra, esta lucha tiene caracteres desgarradores, que marcan la historia y la memoria de las sociedades del continente, comprometiendo su futuro. Surge entonces, a partir de estos acontecimientos, una fuerte vertiente narrativa, que elabora poco a poco un discurso que, desde la perspectiva soleada de la independencia como proyecto, se sume en la oscuridad de la herida poscolonial: las dictaduras, el militarismo, la destrucción. Son textos que expresan el universo histórico vivenciado, y construyen la memoria de un continente antiguo y joven al mismo tiempo. Se trata de la novela africana de las independencias, cuyas raíces están por una parte en la historia secular de una civilización y por otra en el pasado reciente de la guerra, pero también evidencian la impronta cultural de la colonización. Apunta la historiadora Lilyan Kesteloot:

Desde 1968, después de El sol de las independencias de Ahmadou Kourouma y El deber de violencia de Yambo Ouologuem, un gran número de conciencias africanas se expresaron, muchas leguas se desataron, escritores se reveleraon, abordando con valentía y lucidez la situación político-social del África 'en vías de desarrollo'. [...] Todos, en grados diversos, habiendo observado los problemas africanos posteriores a las independencias, se negaron a mantener la visión utopista de la negritud. Prefirieron la verdad del testimonio sincero.

Y esta sinceridad tuvo frutos, pues muchas de estas novelas eran excelentes. Los nuevos escritores tenían tendencia a optar por un estilo realista bastante sobrio a veces cercano a la escritura periodística. Pero que dejaba transparentar toda la complejidad de las convulsiones a menudo tragicómicas del África en mutación ${ }^{2}$ (KESTELOOT, 2001, p. 255).

\footnotetext{
2 "Depuis 1968, après Le soleil des Indépendances d'Ahmadou Kourouma et Le devoir de violence de Yambo Ouologuem, un grand nombre de consciences africaines se sont exprimées, bien de langues ce sont déliées, des écrivains ce sont révélés, en abordant avec courage et lucidité la situation politicosociale de l'Afrique 'en voie de développement'. [...] Tous, à degrès divers, ayant observé les problèmes africains survenus
} 
Más allá de otros géneros que ven la luz en ese momento, como el ensayo, la poesía, el teatro, este surgimiento y desarrollo de un relato novelístico africano al que nos referimos tiene nombres claros: Pepetela, en la parte de lengua portuguesa; Sembene Ousmane, Sony Labou Tansi, Ahmadou Kourouma en la de lengua francesa; Wole Soyinka en la anglófona, entre los más conocidos. En los otros géneros podemos encontrar tantos otros intelectuales preocupados por problemas diferentes relativos a su espacio pero al final comunes: grandes intelectuales como Ki Zerbo, Hampaté Bâ, Amilcar Cabral, Samir Amin. Este último ha tenido una importante vinculación, a través de las redes de las Ciencias Sociales de los sesenta y en especial de CLACSO y sus reuniones, con los intelectuales de América Latina, así como, posteriormente, en los años ochenta a través de los proyectos de UNRISD en Naciones Unidas, dirigido por Enrique Oteiza, quien, como en CLACSO, privilegió en su trabajo la constitución de estas redes sur-sur.

Había en común entre las culturas africanas la oralidad, como pilar central de una propuesta creativa. Las culturas orales previas a la colonización continuaron su desarrollo paralelamente a los otros sistemas culturales, más allá de la diáspora producida por la esclavitud. Esta última aparece hoy como la primera vinculación cultural entre ambos continentes, revivida en grandes novelas como la de Maryse Condé, Moi, Tituba, sorcière, del Caribe francófono, o la relativamente reciente de Ana Maria Goncalves, brasileña, Um defeito de cor. Son ellas reelaboraciones que se sumergen en la memoria colectiva del proceso esclavista, adentrándose en la creación sólida de su vida cotidiana, desde una mirada de mujer, reconstruyendo y construyendo a la vez la otra historia, y generando así un nuevo tipo de narrativa histórica. Se trata de un relato que asume la historia desde otro lugar, que le da un espacio de vida cotidiana, pero que además elabora la historia a partir de memorias dejadas al margen.

Así como la oralidad es materia que construye la enunciación en textos fundamentales de América Latina, como los relatos de Juan Rulfo, lo es también en los relatos africanos, como los de Kourouma o Labou Tansi. Por una parte, la oralidad en sí misma en ambos continentes es una realidad vigente. Ella reproduce y produce textualidades. Más allá de los ecos residuales de las culturas africanas que se rescatan en formas musicales, perspectivas de vida, cultos, los personajes saltan de un continente a otro con la memoria de la esclavitud: la araña (Anancy), el conejo o

\footnotetext{
après les indépendances, refusèrent de rester figés sur la vision utopiste de la négritude.Ils préfèrent la vérité du témoignage sincère. / Et cette sincérité porta ses fruits, beaucoup de ces romans et de ces nouvelles étaient excellents. Les nouveaux écrivains avaient tendance à opter pour un style réaliste assez sobre parfois proche de l'écriture journalistique. Mais laissant transparaître à merveille toute la complexité des convulsions souvent tragicomiques de l'Afrique en mutation."
}

la tortuga, propios de la imaginería de la costa occidental de Africa. La existencia de sistemas paralelos de oralidad y escritura, de sistemas literario-culturales en lenguas autóctonas y de procesos de apropiación de los contenidos del imaginario popular, así como de las estructuras del lenguaje y las formas de relación con la vida, que generan formas de subversión de las lenguas metropolitanas, es lo propio de ambas formaciones culturales. Todo esto a partir de un común efecto de la colonización, de la memoria de la esclavitud y de la vigencia del racismo en sus estructuras socio-culturales.

Debido a la coexistencia de tiempos disímiles que se articulan y desarticulan en una andadura propia de las sociedades periféricas, la relación del continente americano con las culturas de África ha sido primero y fundamentalmente con las sociedades diaspóricas propias del proceso de esclavitud atlántica, pero hay también, desde los años 1960 y a partir de la internacionalización de la novela latinoamericana, una relación directa, en donde algunos escritores africanos reconocen en la voz de los escritos latinoamericanos (como Sony Labou Tansi en el Congo en relación a García Márquez) formas y resonancias, estructuras del pensamiento que se aproximan a las suyas. La existencia de este fenómeno tiene que ver evidentemente con la común esfera colonial en la que ambas culturas han debido desarrollarse.

Es por eso que en ambos continentes la inflexión independentista se da en la búsqueda del perfil de sus identidades. Seguramente es esta misma condición, la incertidumbre y la pluralidad que ella implica lo que hace que la narración histórica ocupe una de las líneas centrales de su producción. Expresar la historia, escribirla, son los modos en que el gesto de la escritura en ambas culturas encuentra el modo de exorcizar sus traumas, de explicar sus vacíos, de responder a sus silencios y también de recuperar su belleza. Así, en la reflexión sobre la esclavitud surge algo que los historiadores africanos hoy discuten: la responsabilidad de los sectores dirigentes locales en la esclavitud atlántica. Y como parte del interés por los estudios poscoloniales, comenzamos a familiarizarnos con nombres de filósofos como los de Achille Mbembe y Valentín-Yves Mudimbe, del África francófona, o Kwame Anthony Appiah, de la anglófona, quienes arrojan miradas críticas a su continente de origen a la vez que buscan recuperar sus modos de pensar, desde una participación en redes internacionales y una inserción en la academia norteamericana como nuevo polo de religación y proyección intelectual.

Sin embargo, junto a estas configuraciones actuales y globales de las "geopolíticas del conocimiento" - como las llama Walter Mignolo - que nos acercan al África en su pensamiento y su escritura conceptual, la diáspora africana hacia América y en América parece continuar hoy en el 
destino de países y sectores involucrados. La historia de los haitianos, que fueron los primeros de insubordinarse frente a la metrópoli francesa - lugar preeminente de la narrativa de Alejo Carpentier -, que desarrollan tempranamente un pensamiento de la negritud, ha tenido un destino histórico aciago con la invasión norteamericana, las dictaduras subsecuentes y la situación actual: la diáspora por razones económicas continúa con su disgregación en los países del continente; y a ella se suman otras diásporas de personas y grupos que llegan como migrantes económicos y políticos directamente de África.

Cuando nos aproximamos a las literaturas y las culturas de África y América, la mirada comparatista nos conduce a asimilar mecanismos de construcción de los discursos de la cultura que las aproximan, así como contenidos diferentes de los materiales en proceso que las alejan, las diferencias en el desarrollo temporal de sus procesos: la mayoría de los nuestros tiene dos siglos, el de ellos cincuenta años. Por otro lado, si en la actualidad los nuevos medios facilitan la comunicación, sigue habiendo impedimentos concretos en cuanto a la circulación de la literatura. Primero, porque a pesar de la configuración babélica que adquiere el mundo hoy y de la importancia del inglés como lingua franca, las diferencias idiomáticas que nos abren a una diversidad de perspectivas de mundo por otro lado obstaculizan nuestra comunicación. De allí el interés que tiene para nosotros el lazo colonial con Guinea Ecuatorial, único país del África subsahariana donde el español es idioma oficial, lo que evidentemente no implica dejar de lado una aproximación a las literaturas en otras lenguas. En segundo término, desde la misma edición, los escritores africanos enfrentan restricciones en sus países de origen, donde no existen públicos ni mercados consolidados, ni tampoco, por lo general, instituciones que apoyen su labor. Por ello, se ven compelidos a publicar y muchas veces a residir en las antiguas metrópolis coloniales, lo que tiene implicaciones en cuanto a una transformación de sus escrituras, al tiempo que nos permite conocer sus propuestas.
Percibimos una comunidad de interrogantes y búsquedas que nos hemos planteado y nos continuamos planteando: ¿qué es lo que denominamos "literatura" en nuestras sociedades? ¿A dónde apunta nuestro arte? ¿Cuál es nuestra vinculación con la metrópoli? ¿En qué lengua escribir? ¿Qué somos y qué es lo que hace nuestra diferencia? ¿Cómo generar puentes con la literatura de ese continente? Como diría Julio Cortázar, más que las respuestas, lo importante es vivir con intensidad las preguntas.

\section{Referencias}

BAUMGARDT, Ursula; BOUNFOUR, Abdellah (Eds.). Panorama des littératures africaines: états des lieux et perspectives. París: L'Harmattan, 2000.

CENTRO CULTURAL PALACIO LA MONEDA. Exposición África. 2013. En Internet: <http://www.ccplm.cl/sitio/2013/ exposicion-africa/>.

DESPESTRE, René. Buenos dias y adiós a la negritud. La Habana: Casa de las Américas, 1986.

FÉDÉRATION INTERNATIONALE DE FOOTBALL ASSOCIATION. Resumen: España gana un torneo que ha enorgullecido a África. 2010. En Internet: <http://es.fifa.com/ tournaments/archive/worldcup/southafrica2010/>.

KESTELOOT, Lilyan. Histoire de la littérature négro-africaine. Paris: Karthala/AUF, 2001.

LIENHARD, Martín. O mar e o mato: historias da escravidão (Congo-Angola, Brasil, Caribe). Salvador: EDUFBA/CEAO, 1998.

ORTIZ, Fernando. Contrapunteo cubano del tabaco y el azúcar. La Habana: Jesús Montero, 1940.

QUINTERO-RIVERA, Ángel. Cuerpo y cultura: las músicas "mulatas" y la subversión del baile. Madrid/Frankfurt am Main: Iberoamericana/Vervuert, 2009.

Recebido: 15 de abril de 2014

Aprovado: 14 de junho de 2014

Contatos: ana.pizarro@usach.cl cbenavem@gmail.com 